\title{
Öğretmen Adaylarının Metin Özetleme Stratejilerini Kullanım Tercihleri
}

\author{
Sevgi ÇALIŞIR ZENCI*
}

\section{$\ddot{O} z$}

Bu çalışma 2019-2020 eğitim öğretim yılında Almanca (39), İngilizce (16), Özel Eğitim (42) Öğretmenliği bölümü 1. sınıfta okuyan 97 öğretmen adayının özetleme stratejilerini kullanım durumlarını incelemeyi amaçlamaktadır. Çalışmada tarama modelinden yararlanılmıştır. Deneme (2009) tarafından geliştirilen 14 maddelik "Özetleme Stratejileri Ölçeği” uygulanmıştır. Çalışmanın sonuçlarına göre, yedinci, birinci, ikinci, on üçüncü, dokuzuncu, onuncu, on birinci ve beşinci maddeler yüksek oranda tercih edilen stratejiler arasındadır. En az kullanılan stratejilerin arasında "Özet boyunca özgün metnin yazarına gönderme yaparım." şeklinde açıklanan strateji olduğu görülmüştür. Az tercih edilen stratejiler arasında "Özet metne konuyla ilgili fikirlerimi de katarım.”, "Özgün metni okumaya başlar başlamaz özet metni yazmaya başlarım.” stratejileri yer almaktadır. "Özgün metnin ana fikrini özet metnin ilk cümlesinde ifade ederim.” stratejisi öğretmen adayları tarafından tercih edilmeyen stratejidir. Öğretmen adaylarının özetleme stratejilerini orta düzeyde tercih ettikleri tespit edilmiştir. Çalışmada cinsiyet değişkenine ilişkin anlamlı bir farklılık tespit edilmemiştir. İngilizce ve Almanca öğretmenliği bölümlerindeki öğrencilerde on ikinci ve on üçüncü maddelerde anlamlı farklılık görülmüştür. Yazılı anlatım ya da Türk dili gibi okuma ve yazmaya yönelik derslerde metin özetleme konusu üzerine hem teorik hem de uygulamaya yönelik çalışmalar yapılmalıdır.

Anahtar Kelimeler: ögretmen adayları, metin, özetleme, strateji, tercih.

* Öğretim Görevlisi Doktor, Anadolu Üniversitesi, Türk Dili Bölümü, Eskişehir, Türkiye.

Elmek: sevgicalisir@anadolu.edu.tr

Orcid: 0000-0002-7942-5452 


\title{
Pre-service Teachers' Preferences of Using Text Summarizing Strategies
}

\begin{abstract}
This study examines the pre-service teachers' preferences of using summarizing strategies in German, English and Special Education Teaching departments in the 2019-2020 academic year in a public university. The study group consisted of 97 pre-service teachers studying in German (39), English (16), and Special Education (42) Teaching departments.

Screening model was used in the study. The 14-item "Summarizing Strategies Scale" developed by Deneme (2009) was applied. According to the results of the study, highly preferred strategies included items 7, 1, 2, 13, 9, 10, 11 and 5. These items are important items in the text summarizing strategies, and it was seen that pre-service teachers were successful in this subject. The least preferred strategy is "I refer to the author of the original text throughout the abstract." (Item 14). It was determined that this item was not preferred by pre-service teachers. Less preferred strategies include the statements "I also add my ideas to the summary text." (Item 4) and "As soon as I start reading the original text, I start writing the summary text" (Item 6). It was also determined that pre-service teachers did not use item 12 ("I express the main idea of the original text in the first sentence of the abstract."). In the study, there was no significant difference regarding the gender variable. In the 12th and 13th items, it was found that there was a significant difference between the English and German Language departments. Both theoretical and practical studies should be carried out on the subject of text summarization in reading and writing courses such as written expression or Turkish language.
\end{abstract}

Kywords: pre-service teachers, text, summarizing, strategy, preference. 


\section{Extended Summary}

\section{Research Problem}

The number of studies has increased along with the development of the scale of text summarization strategies. Although the studies were carried out in different years, it was seen that the strategies that students preferred or did not prefer did not differ. This study was deemed necessary to determine the use of students' text summarization strategies in the 2019-2020 academic year and to determine whether there is a difference or not.

This study aims to determine the preferences of pre-service teachers who study in German and English Language Teaching Departments and Special Education Teaching Department regarding text summarization strategies, and whether there is a significant difference according to gender and the departments they study.

\section{Literature Review}

It is seen that the studies used the same scale but different sample populations to determine text summarization strategies. Deneme (2009) examined prospective English teachers' tendency to use summarizing strategies. Erdem (2012) used Turkish language and literature pre-service teachers as a sample, and Eyüp, Stebler and Uzuner Yurt (2012) selected Turkish teacher candidates as their sample. There are also studies on the use of techniques to improve text summarization skills. Duran and Özdil (2019) aimed to determine the investigation of PQRST techniques in the development of text summarizing skills of primary school fourth grade students. It is designed according to the development of the summarizing skill of the PQRST technique. There is also a study on summarizing activities in textbooks. Karadağ (2019) examined the summarizing activities included in the Turkish secondary school textbooks used in the 2018-2019 academic year. The main result of the research is that most of the summarizing activities in all Turkish textbooks are not formed appropriately in accordance with the cognitive processes of summarizing and they come to- 
gether. Along with the text summarization strategies, studies have increased in terms of implementation. Although studies are evaluated differently, it is seen that the strategies students prefer do not differ. It is necessary to determine how they use the necessary text summarization strategies in the 2019-2020 academic year and to see whether there is a difference or not.

\section{Methodology}

Pre-service teachers' preferences of using summarizing strategies in German Language Teaching, English Language Teaching and Special Education Teaching departments are examined in the 2019-2020 academic year in a public university. The screening model was used in the study. The study group consisted of 97 prospective teachers studying in German (39), English (16), and Special Education (42) Teaching departments. The 14-item "Summarizing Strategies Scale" developed by Deneme (2009) was applied. Firstly, the data was evaluated according to departments, and frequency and percentage were used at this stage. Independent sample $t$ test was used to determine whether gender plays a role, and one-factor analysis of variance (ANOVA) was used to determine whether there was a difference between the departments. Tukey HSD was used in multiple comparison analysis to determine the differences between groups.

\section{Results and Discussion}

When highly preferred strategies are examined, it is seen that pre-service teachers read the entire original text before using the summary text, use appropriate conjunctions between sentences, eliminate unimportant information, do not include this information in the abstract text and create the abstract text by considering the structure of the original text. In this respect, Eyüp coincides with the works of Stebler and Uzuner Yurt (2012) and Erdem (2012). In this study, $76 \%$ of prospective teachers stated that they paid attention to writing in the appropriate length. It is one of the highly preferred strategies. In this respect, it does not coincide with the trial of Trial (2009). Similarly, it does not coincide with the work of Eyüp, Stebler and Uzuner Yurt (2012), who stated that approximately $40 \%$ of the teacher candidates wrote randomly while writing a summary without any limitation on the length. As a result of the study of Trial 
(2009), the strategy of writing the abstract text taking into account the structure of the original text was preferred at a very low rate. In this respect, it does not correspond to this study.

The strategies preferred at the medium level include eleventh, fifth, fourth, twelfth and third items. In this respect, Eyüp coincides with the work of Stebler and Uzuner Yurt (2012), Erdem (2012) and Deneme (2009). The preservice teachers preferred to use the main idea of the original text partially in the first sentence of the abstract text, to partially add their ideas to the abstract text and to include some of the examples in the original text in the abstract text.

Among the low-preferred strategies, the statement, "As soon as I start reading the original text, I begin to write abstract text." (Item six) comes first. In this respect, it does not coincide with the result of Deneme (2009) 's work. Deneme (2009) stated that students use this strategy in their study. Instead of using the strategy in the sixth item, pre-service teachers preferred the seventh item ("Before I summarize anything, I read the entire text in order to fully understand the original text"). One of the low-preferred strategies in the study is to refer to the author of the original text $(10 \%)$. Similarly, in Eyüp, Stebler and Uzuner Yurt's (2012) study, this rate is very low (8.2\%). In the study of Erdem (2012), it was revealed that prospective teachers of Turkish language and literature do not use this strategy adequately. Deneme (2009) also stated that the rate of this strategy is very low in his study.

In the study, it was also investigated whether gender and department had an effect on the use of summarization strategies. Students' use of text summarization strategies does not differ significantly by gender. Similarly, in Erdem (2012) 's study, there was no significant difference regarding the gender variable. In the study of Eyüp, Stebler and Uzuner Yurt (2012), gender variable was not included. In the study of Deneme (2019), the majority of the participants were women.

It is seen that the preference rates of the strategies do not differ much between the groups. It has been determined that there is a significant difference between the students studying in the German Language Teaching Department and English Language Teaching Department only in the twelfth and thirteenth items. 



\section{Giriş}

Metin özetleme, daha çok bir metnin okunup anlaşılması sürecinden sonra önemli noktalara değinilerek metnin kısaltılması olarak tanımlanabilir. Özetleme, öğrencilerin özgün metinden daha özlü ve yoğun biçimde yeniden bir metin oluşturmaya yönlendirdiği için üretken bir işlemdir. Öğrenciler özgün metnin özünü yansıtan fikirleri tanımlayarak, birleştirerek özgün metni yeniden yapılandırır ve düzenler (Hidi ve Anderson, 1986). Çıkrıkçı (2008) özetlemeyi, önemli bilgiyi daha az önemli bilgiden ayırma yoluyla, kaynak metin üzerinde gerçekleştirilen işlevsel bir kısaltma eylemi olarak tanımlamaktadır. Ülper ve Karagül (2011) özetlemeyi bir edim olarak niteleyerek, bir kaynak metnin bilişsel işlemler sonucunda daha kısa bir metne dönüştürülme işlemi, Deneme (2009) bireyin ne öğrendiğini düşünmesi, mantıksal ve anlaşılabilir tarzda yazması ve kendi kelimeleriyle ne öğrendiğini açıklaması biçiminde tanımlamaktadır. Özçakmak (2015)'e göre özetleme, yazılı ya da sözlü bir metnin önemli yönlerini, onu okumayan ya da dinlemeyen birisinin anlayabileceği şekilde, özlü, kapsayıcı ve kısaca ifade etmesidir. Senemoğlu (2018), özetlemeyi bilişsel bir ürün olarak ele almaktadır.

Öğrenim açısından bakıldığında özetleme okuduğunu anlama, gerekli bilgiyi gereksiz bilgiden ayırt etme gibi işlemler gerektirdiğinden zor bir beceri olduğu söylenebilir. Cemiloğlu ve Ogur (2016) metnin özetini çıkarmanın bir çeşit anlama stratejisi olduğunu belirterek bireyin metinden anladıklarını kendi cümleleri ile ifade edeceği için yapılan işlemin bir anlamda metni yeniden anlamlandırma olduğunu, bu anlamlandırmanın da mantık akışını gerektirdiğini belirtmişlerdir. Gerek öğrenim gerekse sosyal hayatta özetlemenin önemli bir rolü olduğu için kişiye kazandırılması gerekmektedir. Alanyazın taramasında özetlemenin hem bir beceri hem de bir strateji olarak ele alındığı görülmektedir. Karatay ve Uzun (2019)'a göre, özetleme, okunan veya dinlenen bir metinde verilmek istenen önemli bilgileri seçme ve kendi cümleleriyle yazılı veya sözlü olarak ifade edebilme becerisidir. Karatay ve Okur (2012) da özetlemeyi bir beceri olarak tanımlamakta, öğrencinin bu beceriyi öğretmen rehberliğinde özetleme tekniklerini kullanmayı öğrenmesine bağlı olarak kazanılabildiğini vurgulamaktadır. 2018 
Y1lı Türkçe Dersi Öğretim Programı incelendiğinde yazma alanı kazanımları içerisinde yazma stratejilerinin de yer aldığı görülmektedir. İlgili programın bütün sınıf düzeyindeki yazma alanı kazanımları incelendiğinde Türkçe derslerinde kullanılabilecek yazma stratejileri içerisinde "özet çıkarma” başlığının da yer aldığ görülmektedir (Milli Eğitim Bakanlığ1, 2018).

Yazılı bir materyalin özetlenmesi etkili bir öğrenme yoludur. Özetleme ile metnin anımsanması kolaylaşır. Özetlemeyi öğrenmek zaman isteyen bir süreçtir ve birtakım stratejilerin kullanılmasını gerektirir. Özetleme, öğrenim hayatının ilk yıllarında başlar ve yükseköğretimde dâhil olmak üzere devam eder. Öğretmenlerin de özetleme becerisini ve stratejilerini bilmesi, öğretimin daha nitelik kazanmas1nı sağlar. Okullarda metnin özetini yazma çalışmaları uygulama anlamında büyük önem arz etmektedir. Öğretmenler öğrencilerini gerek ödevlerle gerek sinavlarda s1k sık özet yazma konusunda teşvik etmektedirler (Slotte ve Lonka, 1999; WadeStein ve Kintsch, 2004; Winograd, 1984). Özbay (2009) özetleme çalışmalarında öğretmenin öncelikle öğrencilerini kontrol etmesi ve yazıların özet niteliği taşıyıp taşımadığını değerlendirmesi gerektiğini vurgulamaktadır. Özet çıkarmayı bilmeyen öğrencilerin sözcükleri kopya ettiklerini belirtmekte ve bu nedenlerle özetleme stratejilerinin öğretiminin çok önemli olduğunu ifade etmektedir. Bu açıdan özetlemede hem öğrencilerin hem de öğretmenlerin dikkat etmesi gereken noktalar vardır.

Özetlemede dikkat edilmesi gereken bazı hususlar bulunmaktadır. Melton (2002'den akt; Belet, 2005: 37) tarafından belirtilen hususlar şunlardır:

- Makaleyi özet yapma amacına uygun olarak okumalıdır.

- Okunulan materyaldeki düşünceleri kendi ifadeleriyle yazmalıdır.

- Materyalde anlatılmak istenen ana fikri bulmalıdır.

- Ayrıntıları sınıflandırılmalıdır.

- Özetlemenin bir sıralaması değil; materyaldekinin bir minyatürü olduğunu unutmamalıdır.

- Bilgileri bir bütün olarak bütünleştirerek yazmalıdır.

- Özeti tekrar okumalı ve gözden geçirmelidir.

Çalışmalarda metin özetleme stratejilerini belirlemek için hedef kitle farklılaşmakla birlikte genellikle metin özetleme stratejileri ölçeği kullanıldığı görülmektedir. Deneme (2009), çalışmasında İngilizce öğretmen adaylarının, Erdem (2012) Türk dili ve edebiyatı öğretmen adaylarının, Eyüp, Stebler ve Uzuner 
Yurt (2012) çalışmasında ise Türkçe öğretmeni adaylarının özetleme stratejilerini kullanmadaki eğilimlerini belirlemeyi amaçlamışlardır. Bunun dışında metin özetleme becerilerinin geliştirilmesine yönelik tekniklerin kullanımı üzerine yapılan çalışmalar da bulunmaktadır. Duran ve Özdil (2019), ilkokul dördüncü sınıf öğrencilerinin metin özetleme becerilerinin geliştirilmesinde PQRST tekniğinin etkisini tespit etmeyi amaçlamışlardır. Araştırmadan elde edilen sonuçlara göre PQRST tekniğinin özetleme becerisinin gelişimine katkı sağlamaktadır. Ayrıca ders kitaplarında yer alan özetleme etkinlikleri üzerine de çalışma bulunmaktadır. Karadağ (2019), 2018-2019 eğitim-öğretim yılında yürürlükte olan ortaokul Türkçe ders kitaplarında yer alan özetleme etkinliklerini incelemiştir. Araştırmada ortaya çıkan en temel sonuç, Türkçe ders kitaplarının tamamında özetleme etkinliklerinin büyük çoğunluğunun özetlemenin bilişsel süreçlerine uygun olarak oluşturulmaması ve öğrencilerden doğrudan bir metnin özetinin istenmesidir. Metin özetleme stratejileri ölçeğinin geliştirilmesi birlikte uygulama anlamında çalışmalar artmıştır. Çalışmalar farklı yıllarda yapılmasına rağmen öğrencilerin tercih ettiği ve etmediği stratejilerin farklılaşmadığı görülmüştür. 2019-2020 öğretim yıllarında öğrencilerin metin özetleme stratejilerinin kullanım durumlarını tespit emek ve bir farklılık olup olmadığını ortaya koymak amacıyla bu çalışmaya gerek görülmüştür.

Bu çalışma Almanca (AÖ), İngilizce (İÖ) ve Özel Eğitim Öğretmenliği (ÖEÖ) bölümlerinde okuyan öğretmen adaylarının metin özetleme stratejilerini kullanma tercihlerini, bu durumun cinsiyete ve okudukları bölümlere göre anlamlı farklılık olup olmadığını belirlemeyi amaçlamaktadır.

\section{Yöntem}

Bu bölümde araştırma modeli, çalışma grubu, verilerin toplanması ve analizine yer verilmiştir.

\section{Araştırma Modeli:}

2019-2020 eğitim öğretim y1lında bir devlet üniversitesinde AÖ, İÖ ve ÖEÖ bölümlerinde öğrenim gören öğretmen adaylarının özetleme stratejilerini kullanım tercihleri betimlenmiştir. Bu grupların seçilmesinin gerekçesi öğretmen adaylarının Türk Dili I ve II derslerini zorunlu olarak almalarıdır. Bu derslerde gerek bilimsel bir metnin özetlenmesi gerek edebi bir metnin özetlenmesi gibi konulara yer verilmektedir. Araştırmada nicel araştırma yöntemlerinden tarama 
modeli kullanılmıştır. Bilindiği üzere tarama modelleri, geçmişte ya da halen var olan bir durumu var olduğu şekliyle betimlemeyi amaçlayan araştırma yaklaşımlarıdır ve araştırmaya konu olan olay, birey ya da nesne, kendi koşulları içinde ve olduğu gibi tanımlanmaya çalışılır (Karasar, 2009).

\section{Çalışma Grubu:}

Çalışma Türk Dili dersi kapsamında gerçekleştirilmiştir. Çalışma grubu Türk Dili dersini alan 1. sınıf Eğitim Fakültesi öğrencilerinden rastlantısal olarak seçilip oluşturulmuştur. Katılımcıların cinsiyet ve bölüme göre dağılımlarıyla ilgili bilgiler Tablo 1'de gösterildiği gibidir.

Tablo 1.

Katılımclların Özellikleri

\begin{tabular}{cccccc}
\hline \multicolumn{7}{c}{ Bölüm } \\
\hline Cinsiyet & Almanca Öğrt. & İngilizce Öğrt. & Özel Ĕ̈itim Öğrt. & Toplam & $\mathbf{\%}$ \\
\hline Kadın & 22 & 11 & 24 & 57 & 59 \\
\hline Erkek & 17 & 5 & 18 & 40 & 41 \\
\hline Toplam & 39 & 16 & 42 & 97 & 100 \\
\hline
\end{tabular}

\section{Verilerin Toplanması ve Analizi:}

Çalışma grubu araştırmaya gönüllülük ilkesi çerçevesinde katılmıştır. Öncelikle katılımcıların cinsiyet ve bölümleri sorulmuş ardından Deneme (2009) tarafindan geliştirilen 14 maddelik “Özetleme Stratejileri Ölçeği” uygulanmıştır. Araştırmada kullanılan ölçek, araştırmacı tarafından Kirkland ve Saunders (1991); Alexander ve Lombardi (2005) ve Flemming (2006)'in çalışmalarında önerilen özet yazma kılavuzu ve kuralları temel alınarak hazırlanmıştır. Kullanılan ölçeğin KR-20 güvenirlik katsayısı (0.88) oldukça yüksektir (Deneme, 2009: 86). Ölçekte yer alan seçenekler Hiçbir zaman=1, Çok nadir=2, Bazen=3, Genellikle=4, Her zaman=5 şeklinde puanlandırılmıştır. Bu araştırmada ölçeğin Cronbach-alfa katsayısı 0.68 bulunmuştur. Alınan veriler öncelikle metin özetleme stratejilerine göre değerlendirilmiştir, bu aşamada istatistiksel işlemlerden yüzde kullanılmıştır. Cinsiyetin rol oynayıp oynamadığını tespit etmek için bağımsız örneklem t testi ve bölüm farklılığının olup olmadığını belirlemek için de tek faktörlü varyans analizi (ANOVA) kullanılmıştır. Gruplar arasındaki farklılıkları belirlemek için çoklu karşılaştırma analizinde Tukey HSD’den yararlanılmıştır. 


\section{Bulgular ve Yorum}

$\mathrm{Bu}$ bölümde öncelikle öğretmen adaylarının tercih ettikleri stratejilerin oranları sunulmuş, ardından cinsiyete ve bölümlere göre farklılık olup olmadığına ilişkin bulgu ve yorumlara yer verilmiştir.

\section{Öğretmen Adaylarının Metin Özetleme Stratejilerini Kullanma}

\section{Tercihlerine İlişkin Bulgular:}

Bu bölümde AÖ, İÖ ve ÖEÖ bölümlerinde öğrenim gören öğretmen adaylarının metin özetleme stratejilerine yönelik yüksek oranda ve orta düzeyde tercih ettikleri aynı zamanda tercih etmedikleri stratejilerin oranları Tablo 2'de verilmiştir.

Tablo 2 .

Öğretmen Adaylarının Metin Özetleme Stratejileri Ölçeğine İlişkin Yüzde Değerleri

\begin{tabular}{cccc}
\hline Madde no & Genellikle & Bazen & Çok nadir \\
\hline \multicolumn{4}{c}{ Yüksek oranda tercih edilen stratejiler } \\
\hline 1 & $\% 96$ & $\% 3$ & $\% 1$ \\
\hline 2 & $\% 87$ & $\% 13$ & - \\
\hline 13 & $\% 86$ & $\% 14$ & - \\
\hline 9 & $\% 83$ & $\% 14$ & $\% 3$ \\
\hline 10 & $\% 80$ & $\% 16$ & $\% 8$ \\
\hline 11 & $\% 76$ & $\% 16$ & $\% 22$ \\
\hline 5 & $\% 59$ & $\% 20$ & $\% 25$ \\
\hline 4 & $\% 55$ & $\% 20$ & $\% 38$ \\
\hline 12 & $\% 40$ & $\% 436$ & $\% 32$ \\
\hline 3 & $\% 24$ & $\%$ düzeyde tercih edilen stratejiler & \\
\hline
\end{tabular}




\begin{tabular}{cccc}
\hline \multicolumn{4}{c}{ Tercih edilmeyen stratejiler } \\
\hline 6 & $\% 6$ & $\% 17$ & $\% 77$ \\
\hline 14 & $\% 10$ & $\% 21$ & $\% 69$ \\
\hline 8 & $\% 15$ & $\% 40$ & $\% 45$ \\
\hline
\end{tabular}

Tablo 2'deki bulgulara göre, yüksek oranda tercih edilen maddeler; yedinci, birinci, ikinci, on üçüncü, dokuzuncu, onuncu, on birinci ve beşinci maddelerdir. Öğretmen adaylarının büyük çoğunluğu herhangi bir metni özetlemeden önce, özgün metni tamamen anlayabilmek için metnin tamamını okuduklarını (yedinci madde) belirtmişlerdir. Yedinci maddenin ortalaması 4.69'dur. Aynı zamanda özet metnin bütünlüğünü ve bağlantılı olmasını sağlamak için cümleler arasında uygun bağlaçlar kullandıklarını (birinci madde), özgün metindeki önemsiz bilgiyi eleyerek özet metinde bu bilgiye yer vermediklerini (ikinci madde), özet metni özgün metnin yapısını dikkate alarak (on üçüncü madde), kendi sözcükleriyle yazdıklarını (dokuzuncu madde), uygun uzunlukta yazmaya dikkat ettiklerini (onuncu madde) belirtmişlerdir. Bu maddelerin ortalaması şu şekildedir: Birinci maddenin ortalamas1 4.24, ikinci maddenin ortalamas1 4.15, on üçüncü maddenin ortalaması 4.05, dokuzuncu maddenin ortalamas1 3.9, onuncu maddenin ortalamas 13.90'dır.

Bu bulgular, grupların büyük çoğunluğu metnin tamamını okuduktan sonra özete geçmeyi tercih etmektedirler. Bağlaçlar metinde anlamsal ve yapısal ilişkiyi sağlamak için kullanılır. Öğretmen adayları özet metni oluştururken uygun bağlaçları kullanmaktadırlar. Aynı zamanda özgün metinde önemli olmayan bilgiyi eledikleri, önemli olan bilgiye ise özet metinlerinde yer verdikleri ve özet metni oluştururken özgün metnin yapısına dikkat ettiklerini, özgün metindeki cümleleri kopyalamak yerine özet metni kendi sözcükleriyle, metni kısaltarak oluşturduklarını göstermektedir.

Orta düzeyde tercih edilen stratejiler arasında on birinci, beşinci, dördüncü, on ikinci ve üçüncü maddeler yer almaktadır. On birinci maddenin ortalamas1 3.67, beşinci maddenin ortalaması 3.40, dördüncü maddenin ortalaması 2.91, on ikinci maddenin ortalaması 2.91, üçüncü maddenin ortalamas1 2.90 'dır. Öğretmen adaylarının özgün metinden notlar alıp daha sonra bu notları kullanarak 
özet yazma (on birinci madde), özgün metindeki ayrıntıları da özetlemeye gayret etme (beşinci madde), özet metne konuyla ilgili fikirlerini de katma (dördüncü madde), özgün metnin ana fikrini özet metnin ilk cümlesinde ifade etme (on ikinci madde), özette özgün metindeki bütün örneklere değinme (üçüncü madde) gibi stratejileri orta düzeyde kullandıkları tespit edilmiştir.

$\mathrm{Bu}$ bulgular, öğretmen adaylarının özet metinde bütün örneklere kısmen yer verdiklerini, özet metni oluştururken kendi görüşlerini katmadıklarını, metindeki ayrıntılara tamamen yer vermediklerini, genellikle not almadan özet oluşturduklarını, özgün metnin ana fikrini de nadiren özet metnin ilk cümlesinde kullandiklarını ortaya koymaktadır.

Öğretmen adayları altınc1, on dördüncü ve sekizinci maddelerdeki stratejileri diğer stratejilere oranla daha az tercih etmişlerdir. Bu maddelerin ortalaması sırasıyla şu şekildedir: 1.90 (altıncı maddenin ortalaması), 2.12 (on dördüncü maddenin ortalaması), 2.57 (sekizinci maddenin ortalaması). Öğretmen adayları "Özgün metni okumaya başlar başlamaz özet metni yazmaya başlarım." (altıncı madde), “Özet boyunca özgün metnin yazarına gönderme yaparım.” (on dördüncü madde), “Özet yazarken özgün metindeki cümlelerin altını çizip bu cümleleri aynen özet metinde yazarım." (sekizinci madde) gibi özetleme stratejilerini çok düşük oranda tercih etmişlerdir.

Metni okumaya başlar başlamaz aynı zamanda özet metne başlamak ayrıntıların kaçırılmamasını sağlar. Ancak bu stratejinin çok düşük oranda tercih edildiği görülmektedir. Öğretmen adayları metnin yazarına gönderimde bulunma stratejisini de çok düşük oranda tercih etmişlerdir. Bu durum öğretmen adaylarının alıntı yapmayı ya da gönderimde bulunmayı bilmediklerinden kaynaklı olabilir. Öğretmen adayları özgün metindeki cümlelerin altını çizmeyi ve özet metinlerinde kullanmayı tercih etmemişlerdir. Bu durum, özgün metindeki önemli noktaları, ayrıntıları ya da ana fikri kaçırabilecekleri ihtimalini ortaya koymaktadır.

\section{Cinsiyete ve Bölümlere İlişkin Bulgular:}

Bu bölümde öncelikle katılımcıların işaretledikleri seçenekler kapsamında cinsiyetin etkisi olup olmadığına ilişkin istatistiksel sonuçlara, ardından gruplar arasındaki betimsel analiz ve ANOVA sonuçlarına yer verilmiştir. 
Tablo 3 .

Cinsiyet Değişkenine İlişkin T-Testi Sonuçları

\begin{tabular}{llll}
\hline Cinsiyet & N & X & SS \\
\hline Erkek & 40 & 3.30 & .38 \\
\hline Kadın & 57 & 3.43 & .40 \\
\hline
\end{tabular}

Katılımcıların metin özetleme strateji tercihlerinde cinsiyetin rolünü tespit etmek amacıyla bağımsız gruplar için t-testi kullanılmıştır. Tablo 3'e göre, cinsiyet ve metin özetleme stratejileri kullanım tercihleri karşılaştırıldığında erkeklerde $(\mathrm{X}=3.30)$ olduğu görülmektedir. Buna karşılık kadınlarda $(\mathrm{X}=3.43)$ şeklindedir. Analiz sonucunda anlamlı farklılık bulunmamıştır ( $p>0.05)$. Öğretmen adaylarının metin özetleme stratejilerini kullanma tercihleri cinsiyete göre anlamlı bir şekilde farklılaşmamaktadır.

AÖ, İÖ ve ÖEÖ bölümlerinde okuyan öğretmen adaylarının betimsel analiz sonuçları Tablo 4'teki gibidir.

Tablo 4.

Gruplar Arasındaki Betimsel Analiz Sonuçları

\begin{tabular}{lccccc}
\hline Bölüm & $\mathbf{N}$ & $\mathbf{X}$ & $\mathbf{S S}$ & En düşük ortalama & En yüksek ortalama \\
\hline AÖ & 39 & 3.28 & .42 & 2.71 & 4.64 \\
\hline İÖ & 16 & 3.62 & .30 & 3.07 & 4.29 \\
\hline ÖЕÖ & 42 & 3.37 & .36 & 2.64 & 4.14 \\
\hline
\end{tabular}

En yüksek ortalamaya sahip öğrenciler, İÖ bölümünde okuyanöğrencilerdir. $(\mathrm{X}=3.62)$. AÖ bölümünde okuyan öğrencilerin ortalamasının diğer gruplara göre daha düşük olduğu görülmüştür. Söz konusu bölümlerde okuyan öğretmen adaylarının özetleme stratejilerini orta düzeyde tercih ettikleri görülmektedir. 
Tablo 5 .

Gruplar Arası ve Grup İçi ANOVA Sonuçları

\begin{tabular}{llllcc}
\hline Varyansın kaynağı & Kareler toplamı & df & Kareler ortalaması & F & P \\
\hline Gruplar arası & 1.335 & 2 & .668 & 4.527 & .013 \\
\hline Gruplar içi & 13.862 & 94 & .147 & & \\
\hline Toplam & 15.198 & 96 & & & \\
\hline
\end{tabular}

Tablo 5'teki ANOVA sonuçlarına göre gruplar arası anlamlı farklılık görülmüştür ( $\mathrm{p}=.013)$. Bunun üzerine hangi gruplar arasında anlamlı farklılık olduğunu tespit etmek amacıyla çoklu karşılaştırma analizlerinden Tukey HSD uygulanmıştır. Buna göre AÖ ve İÖ bölümü arasındaki farkın anlamlı olduğu saptanmıştır $(\mathrm{p}=.009)$. Bu farklılı̆̆ın da ölçeğin $12(\mathrm{p}=.008)$ ve 13. $(\mathrm{p}=.028)$ maddelerinden kaynaklandığg görülmektedir.

\section{Sonuç ve Tartıșma}

Bu çalışmada Eğitim Fakültesinde (AÖ, İÖ ve ÖEÖ bölümleri) okuyan öğretmen adaylarının metin özetleme stratejilerini kullanma tercihleri incelenmiştir. Öğretmen adaylarının özetleme stratejilerini yüksek, orta ve düşük düzeyde tercih ettikleri tespit edilmiştir.

Yüksek oranda tercih edilen stratejiler incelendiğinde öğretmen adaylar1nın özet metne başlamadan önce özgün metnin tamamını okudukları, cümleler arasında uygun bağlaçlar kullandıkları, önemsiz bilgiyi eleyerek, özet metinde bu bilgiye yer vermedikleri ve özgün metnin yapısını dikkate alarak özet metni oluşturdukları görülmektedir. Bu açıdan Eyüp, Stebler ve Uzuner Yurt (2012)'un ve Erdem (2012)' in çalışmalarıyla örtüşmektedir. Bu çalışmada öğretmen adaylarının \%76'sı uygun uzunlukta yazmaya dikkat ettiklerini belirtmişlerdir. Yüksek oranda tercih edilen stratejilerden biridir. Bu açıdan Deneme (2009)'nin çalışmasıyla örtüşmemektedir. Benzer biçimde Eyüp, Stebler ve Uzuner Yurt (2012)'un çalışmasıyla da örtüşmemektedir. Araştırmacıların çalışmasında öğretmen adaylarının yaklaşık \% 40'nın özet yazarken uzunluk konusunda herhangi bir sınırlama yapmadan rastgele yazdıklarını belirtmişlerdir. Deneme (2009)'nin çalışmasının sonucunda özet metni özgün metnin yapısını dikkate alarak yazma stratejisi çok düşük oranda tercih edilmiştir. Bu açıdan bu çalışmayla örtüşmemektedir. 
Orta düzeyde tercih edilen stratejiler arasında on birinci, beşinci, dördüncü, on ikinci ve üçüncü maddeler yer almaktadır. Bu açıdan Eyüp, Stebler ve Uzuner Yurt (2012)'un, Erdem (2012)'in ve Deneme (2009)'nin çalışmalarıyla örtüşmektedir. Öğretmen adayları özgün metnin ana fikrini özet metnin ilk cümlesinde kısmen kullanmayı, özet metne fikirlerini kısmen katmayı ve özgün metinde geçen örneklerin bir kısmına özet metinde yer vermeyi tercih etmişlerdir.

Düşük düzeyde tercih edilen stratejiler arasında ilk sırada "Özgün metni okumaya başlar başlamaz özet metni yazmaya başlarım.” (altıncı madde) maddesi yer almaktadır. Bu açıdan Deneme (2009)'nin çalışmasının sonucuyla örtüşmemektedir. Deneme (2009) çalışmasında söz konusu stratejiyi öğrencilerin kullandıklarını belirtmiştir. Altıncı maddedeki stratejiyi kullanmak yerine öğretmen adayları yedinci maddeyi ("Herhangi bir şey özetlemeden önce, özgün metni tamamen anlayabilmek için, metnin tamamını okurum.") en yüksek oranda tercih etmişlerdir. Çalışmada düşük oranda tercih edilen stratejilerden biri de özgün metnin yazarına gönderme yapmadır (\%10). Benzer biçimde Eyüp, Stebler ve Uzuner Yurt (2012)'un çalışmasında da bu oran çok düşüktür $(\% 8,2)$. Erdem (2012)'in çalışmasında da Türk dili ve edebiyatı öğretmen adaylarının bu stratejiyi yeterli düzeyde kullanmadıkları ortaya konmuştur. Deneme (2009) de çalışmasında bu stratejinin oranının çok düşük olduğunu belirtmiştir.

Çalışmada aynı zamanda cinsiyetin ve bölümün özetleme stratejilerinin kullanımına etkisi olup olmadığı araştırılmıştır. Öğrencilerin metin özetleme stratejilerini kullanma durumu cinsiyete göre anlamlı bir farklılık göstermemektedir. Benzer biçimde Erdem (2012)'in çalışmasında cinsiyet değişkenine ilişkin anlamlı bir fark edilmemiştir. Eyüp, Stebler ve Uzuner Yurt (2012)'un çalışmasında ise cinsiyet değişkenine yer verilmemiştir. Deneme (2019)'nin çalışmasında katılımcıların büyük çoğunluğu kadınlardan oluşmaktadır.

Stratejilerin tercih edilme oranlarının gruplar arasında çok da farklılaşmadığı görülmektedir. Sadece on ikinci ve on üçüncü maddelerde İÖ ve AÖ bölümlerinde okuyan öğrenciler arasında anlamlı bir farklılık olduğu tespit edilmiştir. İÖ bölümünde okuyan öğrencilerin \%43’ü özgün metnin ana fikrini özet metnin ilk cümlesinde ifade ettiklerini, AÖ bölümünde okuyan öğrenciler ise \%20 oranında bu stratejiyi tercih ettiklerini belirtmişlerdir. İÖ bölümünde okuyan öğrencilerin 
tamamı özet metni yazarken özgün metnin yapısını dikkate alarak yazdıklarını belirtirken, AÖ bölümünün bir kısmı bu duruma dikkat ettiklerini belirtmişlerdir.

Çalışmanın sonuçlarına dayanarak öğretmen adaylarına metin özetleme konusunda hem teorik hem de uygulamaya dayalı öğretim yapılması gerekmektedir. Öğretmen adaylarının ölçeğe verdikleri seçenekleri test edebilmek adına uygulama çalışmaları üzerinde de incelemenin yararlı olacağı düşünülmektedir. 


\section{Kaynakça}

Belet, Ş. D. (2005), Öğrenme Stratejilerinin Okuduğunu Anlama ve Yazma Becerileri ile Türkçe Dersine İlişkin Tutumlara Etkisi, Anadolu Üniversitesi Eğitim Bilimleri Enstitüsü: (yayımlanmamış doktora tezi).

Cemiloğlu, M. ve Ogur, E. (2016), “Okuma Öğretiminde Biliş ve Üst-Biliş Stratejileri”, Uluslararası İnsan ve Sanat Araştırmaları Dergisi, 1(1), 46-53.

Çıkrıkçı, S. (2008), “İlköğretim Öğrencilerinde Özetleme Becerisinin Gelişimi”, Dil Dergisi, $141,19-35$.

Deneme, S. (2009), "İngilizce Öğretmen Adaylarının Özetleme Stratejilerini Kullanım Tercihleri”, Journal of Language and Linguistic Studies, 5(2), 85-91.

Duran, E. ve Özdil, Ş. (2019), "Metin Özetleme Becerisinin Geliştirilmesine Yönelik Eylem Araştırmasi: PQRST Tekniği”, Milli Eğitim Dergisi, 48(221), 215-230.

Erdem, C. (2012), “Türk Dili ve Edebiyatı Öğretmen Adaylarının Özetleme Stratejilerini Kullanım Tercihleri ve Metin Dil Bilimsel Bir Özetleme Çalışması”, Dil ve Edebiyat Eğitimi Dergisi, C.1, S.3, ss.36-52.

Eyüp, B., Stebler, Z. ve Uzuner Yurt, S. (2012), “Türkçe Öğretmeni Adaylarının Özetleme Stratejilerini Kullanmadaki Eğilimleri”, Dil ve Edebiyat Eğitimi Dergisi, C.1, S.1, ss.22-30.

Hidi, S., \& Anderson, V. (1986), "Producing Written Summaries: Task Demands, Cognitive Operations, and Implications For Instruction", Review of Educational Research, 56, 473-493.

Karadağ, Ö. (2019), “Türkçe Ders Kitaplarında Yer Alan Özetleme Etkinlikleri Üzerine Bir Değerlendirme”, Ana Dili Eğitimi Dergisi, 7(2), 469-485.

Karasar, N. (2009), Bilimsel Araştırma Yöntemi, 20. Baskı, Nobel Yayın Dağıtım, Ankara.

Karatay, H. ve Okur, S. (2012), "Öğretmen Adaylarının Öyküleyici ve Bilgilendirici Metinleri Özetleme Becerileri”, The Journal of Academic Social Science Studies, (5), 7, ss. 399-420.

Karatay, H. ve Uzun, O. (2019), "Seçici Dinleme Stratejilerinin Öğretimi ile 5. Sinıf Öğrencilerinin Dinlediğini Not Alma ve Özetleme Becerilerinin Geliştirilmesi”, Millî Eğitim Dergisi, Cilt: 48/1, (9-30).

MEB (2018), Türkçe Dersi Öğretim Programı, Ankara: MEB Yayını.

Özbay, M. (2009), Türkçe Özel Öğretim Yöntemleri II, Ankara: Öncü Kitap.

Özçakmak, H. (2015), “Türkçe Öğretmeni Adaylarının Not Alarak Dinlemede Özetleme Stratejilerini Kullanma Becerileri”, Gazi Üniversitesi Eğitim Bilimleri Enstitüsü: (yayımlanmamış doktora tezi).

Senemoğlu, N. (2018), Gelişim Öğrenme ve Öğretim-Kuramdan Uygulamaya, Ankara: Anı Yayınc1lik. 
Slotte, V., \& Lonka, K. (1999), "Review and Process Effects of Spontaneous Note-taking On Text Comprehension”, Contemporary Educational Psychology, 24, 1-20.

Ülper, H., ve Karagül, S. (2011), “Özetleme Becerisinin Kazandırılmasına Yönelik Etkinlikler: Ders Kitapları Temelinde Bir Araştırma”, Türkçe Öğretimi Üzerine Çalışmalar, İzmir: Dokuz Eylül Üniversitesi Yayınları, 145-155.

Wade-Stein, D., \& Kintsch, E. (2004), "Summary Street: Interactive Computer Support For Writing", Cognition and Instruction, 22, 333-362.

Winograd, P. N. (1984), “Strategic Difficulties In Summarizing Texts”, Reading Research Quarterly, 19, 404-425. 